\title{
Infantile Hepatic Hemangioendothelioma: An Uncommon Cause of Persistent Pulmonary Hypertension in a Newborn Infant
}

\author{
Trassanee Chatmethakul, MD ${ }^{1}$ Ramachandra Bhat, MD ${ }^{1} \quad$ Maryam Alkaabi, MD ${ }^{1} \quad$ Abdul Siddiqui, MD ${ }^{1}$ \\ Keith Peevy, MD ${ }^{1}$ Michael Zayek, MD ${ }^{1}$ \\ ${ }^{1}$ Department of Pediatrics, University of South Alabama, Mobile, \\ Alabama \\ Am J Perinatol Rep 2016;6:e260-e263. \\ Address for correspondence Ramachandra Bhat, MD, Department of \\ Pediatrics, University of South Alabama, 1700 Center Street, Mobile, \\ AL 36608 (e-mail: rbhat@health.southalabama.edu).
}

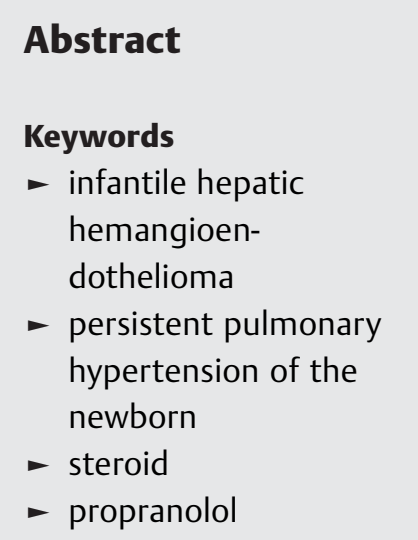

Multifocal and diffuse infantile hepatic hemangioendotheliomas commonly present with signs of high-output congestive heart failure. In addition, prolonged persistent pulmonary overcirculation eventually leads to the development of pulmonary hypertension at a later age. We report a 2-day old, full-term infant with multifocal, large infantile hepatic hemangioendothelioma, who presented with an early onset of pulmonary hypertension, managed successfully with supportive care and systemic therapy directed toward the involution of infantile hepatic hemangioendothelioma.
Significant postnatal circulatory adjustments occurring during the first few hours after birth transform high-resistance pulmonary vasculature into a low-resistance vascular bed, failure of which results in the development of persistent pulmonary hypertension of the newborn (PPHN). ${ }^{1}$ Etiologies of PPHN are very diverse and include pulmonary hypoplasia, congenital diaphragmatic hernia, parenchymal lung diseases, sepsis, perinatal depression, and in utero medication exposure (nonsteroidal anti-inflammatory and selective serotonin reuptake inhibitor). ${ }^{2}$ Neonatal thyrotoxicosis ${ }^{3}$ and systemic arteriovenous fistulas $^{4-7}$ are some the rare causes of PPHN. While it is well known that large infantile hepatic hemangioendotheliomas (IHHs) can act as systemic arteriovenous conduit, manifesting with high-output congestive cardiac failure, ${ }^{8}$ but presentation of IHH in the immediate postnatal period with PPHN is very rare. A high index of suspicion is required to evaluate for $\mathrm{IHH}$ among infants presenting with unexplained pulmonary hypertension during the early postnatal period.

received

February 1, 2016 accepted after revision May 31, 2016

\section{Case Report}

A healthy appearing 39-week African-American male infant was born to a 35 -year-old $\mathrm{G}_{4} \mathrm{P}_{3}$ (Gravida 4 and Para 3 ) mother with a prenatal history significant for chronic hypertension treated with methyldopa, and an abnormal triple screen with a normal karyotype on amniocentesis. He was born by an uncomplicated labor and delivery, with unremarkable physical findings, normal vital signs, and an uneventful clinical course during the first postnatal day. On the second postnatal day, an echocardiogram was performed secondary to a newly developed loud, holosystolic murmur at the left lower sternal border. It revealed a normally structured heart with maximum tricuspid regurgitation jet velocity of $4.4 \mathrm{~m} / \mathrm{s}$ (estimated right ventricular systolic pressure of $77 \mathrm{~mm} \mathrm{Hg}$ ) and dilated right atrium and right ventricle, indicative of PPHN (-Fig. 1). As he was clinically asymptomatic with normal pre- and postductal oxygen saturation $\left(\mathrm{SpO}_{2}\right)$ and normal four extremities blood pressures, his care was continued in the newborn nursery. At

Copyright $\odot 2016$ by Thieme Medical Publishers, Inc., 333 Seventh Avenue, New York, NY 10001, USA. Tel: +1(212) 584-4662.
License terms

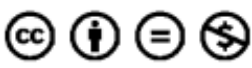




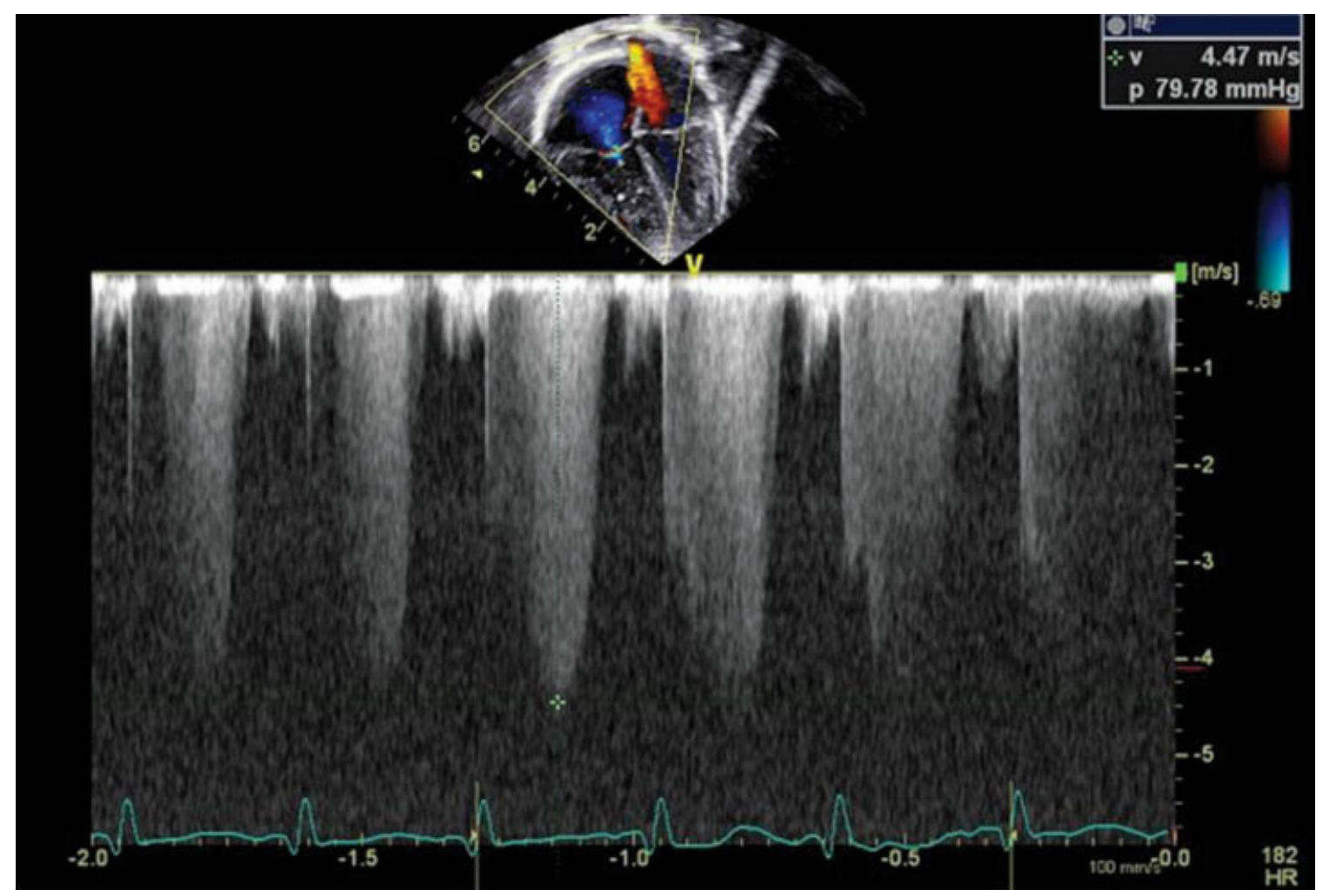

Fig. 1 Echocardiogram showing tricuspid regurgitation with peak jet velocity of $4.4 \mathrm{~m} / \mathrm{sec}$.

72 hours of age, he was transferred to the neonatal intensive care unit (NICU) for irritability, poor feeding, and tachypnea. On admission to the NICU, his examination revealed an irritable infant with tachypnea, mild retractions, and tachycardia. Cardiovascular examination revealed a hyperdynamic precordium, a loud second heart sound, a grade 3/6 holosystolic murmur best heard at the left lower parasternal border, with no thrill and no sternal heave. Breath sounds were equal bilaterally with no audible crackles. The liver was palpable $4 \mathrm{~cm}$ below the right and left costal margin and extending to the epigastrium, with a bruit heard over the liver on auscultation. There was no splenomegaly and no vascular malformations noted over the skin. In view of the presence of hepatomegaly, liver ultrasonography was performed, which showed a heterogeneous liver with multiple isoechoic and hyperechoic masses in both lobes of the liver. Color Doppler imaging showed internal and peripheral color flow, suggesting a possible vascular malformation. Magnetic resonance imaging (MRI) scan of the abdomen showed hepatomegaly with multiple areas of rounded masses with increased T2/STIR signal intensities and low TI/VIBE signal intensities. Following injection of contrast material, the lesions showed increased signal intensities. Mild tapering of the abdominal aorta was noted below the origin of the celiac axis. All these findings suggested multifocal IHH of the liver with a significant left to right shunting. Chest radiograph revealed a mildly enlarged cardiac silhouette with increased pulmonary vascularity without pulmonary infiltrations. A complete blood count showed mild anemia and thrombocytopenia with no evidence of microangiopathic hemolysis. Liver function tests showed mildly elevated liver enzymes. Laboratory evaluation of disseminated intravascular coagulation yielded negative results. Biochemical evaluation of pulmonary hypertension revealed markedly elevated $(>5,000 \mathrm{pg} / \mathrm{mL})$ B-natriuretic peptide (BNP). There was no evidence of prerenal azotemia (blood urea nitrogen: 10 ; creatinine: 0.49 ). Serum $\alpha$-fetoprotein level was within normal limits for the neonatal period.

As PPHN was secondary to increased pulmonary blood flow from arteriovenous shunting at the level of $\mathrm{IHH}$, the infant was managed with fluid restriction and diuretics. Target saturation was set at 95\% to prevent worsening of pulmonary hypertension. However, the infant did not require oxygen to achieve the target saturation range. To enhance the involution of $\mathrm{IHH}$, oral prednisolone $(4 \mathrm{mg} / \mathrm{kg} /$ day, in 2 divided doses) and oral propranolol $(0.6 \mathrm{mg} / \mathrm{kg} /$ day, in 3 divided doses) were started. The dose of propranolol was increased by $0.5 \mathrm{mg} / \mathrm{kg} /$ day, once in every 3 to 4 days to a maximum dose of $2 \mathrm{mg} / \mathrm{kg} /$ day. To monitor the improvement in PPHN, serial BNP (twice weekly) and serial echocardiograms (twice weekly) were performed. Over the next 3 weeks, as an evidence of response to medical management, serial BNP levels showed a significant reduction and was normal $(<100 \mathrm{pg} / \mathrm{mL})$ at the time of discharge. On serial echocardiograms, pulmonary arterial pressure showed a decreasing trend with normal pulmonary arterial pressure and no evidence of right ventricular hypertrophy or dilatation at the time of discharge. Postdischarge follow-up visits confirmed the continued response to treatment. Currently, the infant is on tapering doses of oral steroid and will remain on propranolol monotherapy for up to 1 year of age. 


\section{Discussion}

Elevated pulmonary vascular resistance (PVR) is the key pathophysiological mechanism for PPHN in the immediate postnatal period. ${ }^{1}$ Systemic arteriovenous fistulas such as cerebral vein of Galen malformation, ${ }^{4-6}$ large cerebral arteriovenous malformations $^{9}$ and hepatic arteriovenous malformations ${ }^{7}$ can lead to an obligatory pulmonary overcirculation and have been reported to manifest with PPHN in the immediate postnatal period. In the index case, the diffuse, large IHH acted as a conduit for systemic arteriovenous shunting ${ }^{10}$ (as in arteriovenous malformations), resulting in the obligatory increase in pulmonary blood flow during the early postnatal pulmonary vasorelaxation and after ductal constriction. Coupled with physiologically elevated PVR, ${ }^{11,12}$ the increase in pulmonary blood flow might have contributed for PPHN in the index case. Increased pulmonary blood flow also would delay the postnatal physiological drop in the PVR, ${ }^{13}$ which might be the other reason for the development of PPHN in the index case. Hence, any infants presenting with unexplained PPHN with evidence of hyperdynamic circulation in the absence of congenital heart disease, the differential diagnosis should include cranial and liver systemic arteriovenous fistulas. Appropriate imaging studies should be obtained. To our knowledge, this is the first case report reporting the association of $\mathrm{IHH}$ with PPHN.

Fetal pulmonary overcirculation because of ductal constriction $^{14}$ (antenatal exposure to nonsteroidal anti-inflammatory medications) and experimental ductal ligation ${ }^{15}$ have shown to result in the vascular remodeling and idiopathic pulmonary hypertension. The consequent sustained increase in fetal pulmonary blood flow is the underlying pathophysiology for pulmonary vascular remodeling. However, with $\mathrm{IHH}$, fetal pulmonary overcirculation is a rare possibility due to the parallel nature of fetal circulation and a markedly elevated fetal PVR. As PPHN resolved rapidly after the interventions that ameliorated increased pulmonary blood flow (diuretics and interventions to regress $\mathrm{IHH}$ ), we speculate that fetal pulmonary vascular remodeling was not present in the index case.

IHH is a benign hepatic vascular tumor consisting of a network of capillary sized and endothelium-lined vessels, occurring more frequently in females. ${ }^{16}$ The International Society for the Study of Vascular Anomalies (ISSVA) classification ${ }^{17}$ categorizes IHH under vasoproliferative vascular tumor and names it as a type of infantile or hepatic hemangioma as it exhibits typical triphasic course (proliferative, plateau, and involution phase) just as in infantile hemangiomas. The newer ISSVA 2015 classification ${ }^{18}$ names it under benign vascular tumor category. Based on the presentation, IHH can be categorized as focal, multifocal, and diffuse types, with focal being the most common type. ${ }^{19,20}$ Most of the affected infants present by 6 months of age, ${ }^{20,21}$ with early onset symptoms indicating significant disease severity, ${ }^{19,20}$ as seen in the index case, where a large multifocal IHH contributed to significant hemodynamic consequences. The majority of untreated diffuse and multifocal IHH progresses to develop high-output congestive heart failure, which would have occurred in the index case if not recognized and treated early. It has been reported that approximately 50 to $60 \%$ of all IHHs have hemodynamically significant shunt to cause leftsided volume overload leading to high-output congestive heart failure. ${ }^{10}$ Although focal IHHs are benign in nature with spontaneous regression, ${ }^{19,20,22}$ diffuse and multifocal

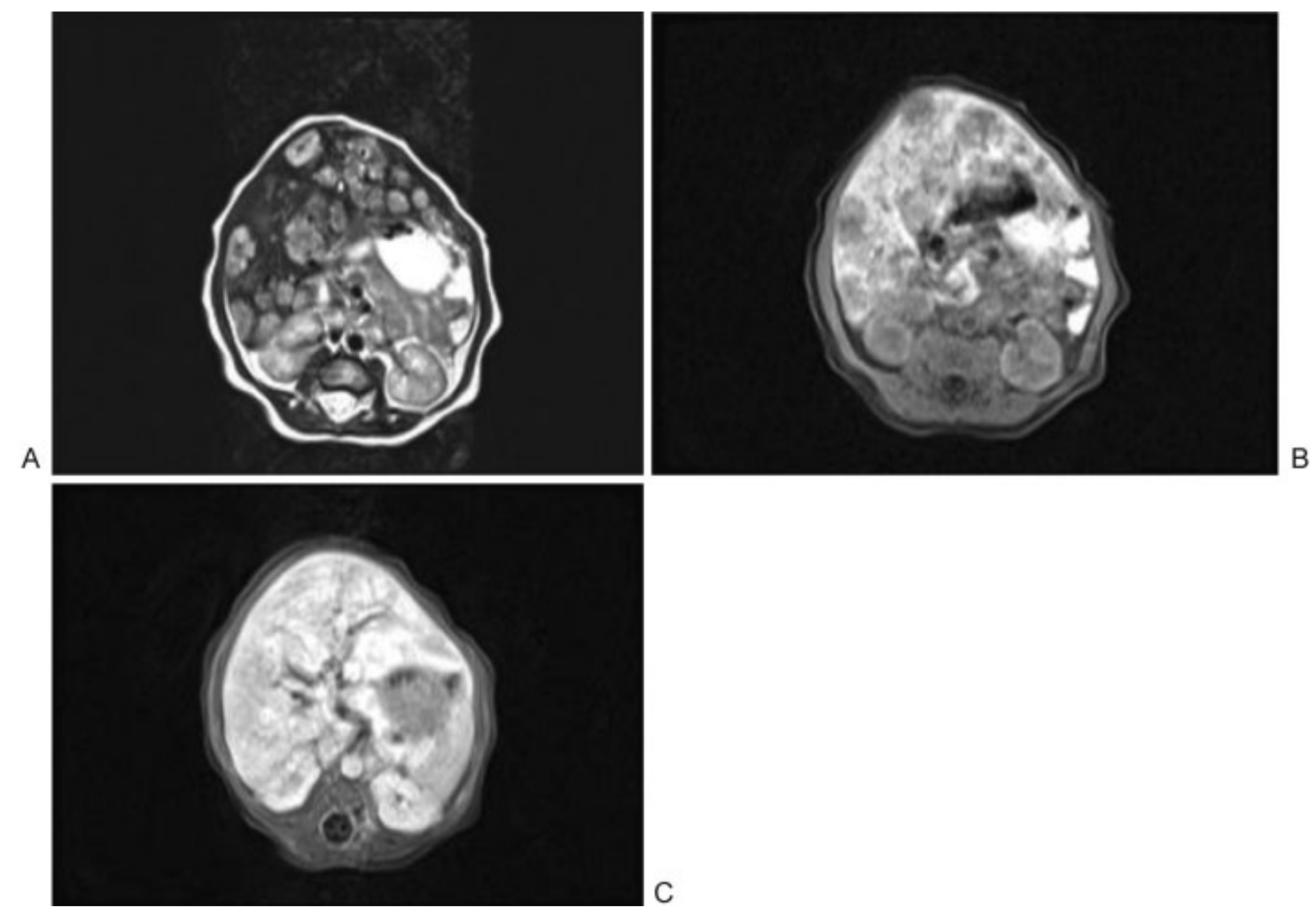

Fig. 2 Liver magnetic resonance imaging showing T2-weighted image, and pre- and post-gadolinium contrast T1-weighted images. 
types manifest with more severe clinical progression to severe cardiac failure, Kasabach-Merritt syndrome with consumptive coagulopathy, intra-abdominal hemorrhage, and liver failure resulting in high mortality. ${ }^{22}$

Even though liver ultrasonography is the most often performed initial diagnostic test for radiologic diagnosis of IHH, MRI is the modality of choice for radiologic confirmation of IHH. Preand postcontrast $\mathrm{T} 1$-weighted images and $\mathrm{T} 2$-weighted axial images are the most useful MRI sequences for diagnosing of IHH (-Fig. 2). ${ }^{10}$ An ultrafast, rapid sequence T2-weighted MRI image sequence has also been described for the follow-up imaging studies to monitor the growth of $\mathrm{IHH}^{23}$

Prompt and effective treatment was important in the index case due to the multifocal nature of the lesion and the clinical presentation. Although currently there are controversies in the management options for $\mathrm{IHH}$, a prolonged oral steroid $^{19,20}$ administration is the mainstay of treatment. However, approximately $25 \%$ of infants with $\mathrm{IHH}$ treated with steroid are completely unresponsive to treatment. ${ }^{19}$ Moreover, propranolol, which is a proven treatment strategy for infantile hemangioma, ${ }^{24}$ has been increasingly used in the management of critical IHH with good results. ${ }^{19,25}$ Hence, the combination treatment strategy of oral steroid and propranolol concurrent with supportive care was initiated to achieve rapid improvement in the clinical symptoms and to prevent complications associated with systemic arteriovenous shunting. To the best of our knowledge, a similar combination treatment strategy for the management of $\mathrm{IHH}$ has been reported previously by Bosemani et al. ${ }^{23}$

In summary, we have reported a case of early symptomatic IHH in a term newborn infant presenting with hyperkinetic PPHN, which was managed successfully with fluid restriction and diuretic use along with systemic pharmacological therapy directed toward enhancing involution of IHH. Our experience emphasizes the importance of a high index of suspicion and prompt evaluation for IHH and related systemic arteriovenous shunts among infants with unexplained pulmonary hypertension with evidence of hyperdynamic circulation.

\section{References}

1 Steinhorn RH. Neonatal pulmonary hypertension. Pediatr Crit Care Med 2010;11(2, Suppl)S79-S84

2 Jain A, McNamara PJ. Persistent pulmonary hypertension of the newborn: advances in diagnosis and treatment. Semin Fetal Neonatal Med 2015;20(4):262-271

3 Obeid R, Kalra VK, Arora P, Quist F, Moltz KC, Chouthai NS. Neonatal thyrotoxicosis presenting as persistent pulmonary hypertension. BMJ Case Rep 2012;2012:5939

4 Hendson L, Emery DJ, Phillipos EZ, Bhargava R, Olley PM, Lemke RP. Persistent pulmonary hypertension of the newborn presenting as the primary manifestation of intracranial arteriovenous malformation of the Vein of Galen. Am J Perinatol 2000;17(8):405-410

5 Selzer G, Rettwitz-Volk W, Schloesser R, et al. Persistent pulmonary hypertension in the newborn infant caused by aneurysm of the vein of Galen [in German]. Klin Padiatr 1993;205(3):190-193

6 Huh J, Noh CI, Choi JY, Yun YS. Pulmonary hypertensive crisis as an initial manifestation of intracranial arteriovenous malformation with aneurysm of the vein of Galen. Int J Cardiol 1998;66(1): 107-109

7 Alexander CP, Sood BG, Zilberman MV, Becker C, Bedard MP. Congenital hepatic arteriovenous malformation: an unusual cause of neonatal persistent pulmonary hypertension. J Perinatol 2006; 26(5):316-318

8 Kim EH, Koh KN, Park M, Kim BE, Im HJ, Seo JJ. Clinical features of infantile hepatic hemangioendothelioma. Korean J Pediatr 2011; 54(6):260-266

9 Long WA, Schall SA, Henry GW. Cerebral arteriovenous malformation presenting as persistent fetal circulation. Diagnosis by cross-sectional echo. Am J Perinatol 1984;1(3):236-241

10 Daller JA, Bueno J, Gutierrez J, et al. Hepatic hemangioendothelioma: clinical experience and management strategy. J Pediatr Surg 1999;34(1):98-105, discussion 105-106

11 Emmanouilides GC, Moss AJ, Duffie ER Jr, Adams FH. Pulmonary arterial pressure changes in human newborn infants from birth to 3 days of age. J Pediatr 1964;65:327-333

12 Gao Y, Raj JU. Regulation of the pulmonary circulation in the fetus and newborn. Physiol Rev 2010;90(4):1291-1335

13 Rudolph AM. The changes in the circulation after birth. Their importance in congenital heart disease. Circulation 1970;41(2): 343-359

14 Alano MA, Ngougmna E, Ostrea EM Jr, Konduri GG. Analysis of nonsteroidal antiinflammatory drugs in meconium and its relation to persistent pulmonary hypertension of the newborn. Pediatrics 2001;107(3):519-523

15 Morin FC III. Ligating the ductus arteriosus before birth causes persistent pulmonary hypertension in the newborn lamb. Pediatr Res 1989;25(3):245-250

16 Selby DM, Stocker JT, Waclawiw MA, Hitchcock CL, Ishak KG. Infantile hemangioendothelioma of the liver. Hepatology 1994; 20(1 Pt 1):39-45

17 Lowe LH, Marchant TC, Rivard DC, Scherbel AJ. Vascular malformations: classification and terminology the radiologist needs to know. Semin Roentgenol 2012;47(2):106-117

18 Wassef M, Blei F, Adams D, et al; ISSVA Board and Scientific Committee. Vascular anomalies classification: recommendations from the International Society for the Study of Vascular Anomalies. Pediatrics 2015;136(1):e203-e214

19 Kuroda T, Kumagai M, Nosaka S, Nakazawa A, Takimoto T, Hoshino K; Infantile Hepatic Hemangioma Study Group, Japan. Critical infantile hepatic hemangioma: results of a nationwide survey by the Japanese Infantile Hepatic Hemangioma Study Group. J Pediatr Surg 2011;46(12):2239-2243

20 Christison-Lagay ER, Burrows PE, Alomari A, et al. Hepatic hemangiomas: subtype classification and development of a clinical practice algorithm and registry. J Pediatr Surg 2007;42(1): 62-67, discussion 67-68

21 Buonomo C, Taylor GA, Share JC, Kirks DR. Abnormalities of the hepatobiliary system. In: Kirks DR, Griscom TN, eds. Practical Pediatric Imaging: Diagnostic Radiology of Infants and Children. 3rd ed. Philadelphia. PA: Lippincott-Raven; 1998:954-979

22 Sevinir B, Ozkan TB. Infantile hepatic hemangioendothelioma: clinical presentation and treatment. Turk J Gastroenterol 2007; 18(3):182-187

23 Bosemani T, Puttgen KB, Huisman TA, Tekes A. Multifocal infantile hepatic hemangiomas-imaging strategy and response to treatment after propranolol and steroids including review of the literature. Eur J Pediatr 2012;171(7):1023-1028

24 Léauté-Labrèze C, Hoeger P, Mazereeuw-Hautier J, et al. A randomized, controlled trial of oral propranolol in infantile hemangioma. N Engl J Med 2015;372(8):735-746

25 Avagyan S, Klein M, Kerkar N, et al. Propranolol as a first-line treatment for diffuse infantile hepatic hemangioendothelioma. J Pediatr Gastroenterol Nutr 2013;56(3):e17-e20 